\title{
Mean platelet volume and its prognostic value in acute coronary syndrome complicated by cardiogenic shock
}

\author{
Karolina Supel, Agata Salska, Filip Jaskiewicz, Michal Kacprzak, Marzenna Zielinska
}

Intensive Cardiac Therapy Clinic, Medical University of Lodz, Poland

\begin{abstract}
Background: Elevated mean platelet volume (MPV) has been recently discussed as a predictor of death in patients with acute coronary syndrome (ACS), but the cut-off point of MPV in relation to poor prognosis has not been estimated so far. The aim of this study was to evaluate $M P V$ and its prognostic value in ACS complicated by cardiogenic shock (CS). Such an analysis in patients with the most serious and fatal complication of ACS has not been performed in previously published research.
\end{abstract}

Methods: Fifty three patients with ACS complicated by CS (age $68.9 \pm 11.4,49 \%$ women, 92\% STEMI, 55\% fatal CS) and 53 age-and gender-matched patients with uncomplicated ACS as a control group (age 69.1 $\pm 10.6,49 \%$ women, $92 \%$ STEMI, 0\% fatal) were included in our prospective study from 2010 to 2012. All the patients underwent successful primary percutaneous coronary intervention. MPV was determined on admission (MPV $\left.V_{1}\right)$ and in consecutive two days of hospitalization $\left(M P V_{2}, M P V_{3}\right)$. The blood sample was analyzed immediately after collection in EDTA tubes using an automatic blood counter.

Results: $M P V_{1}$ was similar in both groups $(8.91 \pm 1.11 \mathrm{fl} v \mathrm{~s} .8 .57 \pm 0.74 \mathrm{fl}$, NS). Furthermore, there were no statistically significant differences in MPV value in fatal and nonfatal CS $(8.90 \pm 1.18 \mathrm{fl}$ vs. $8.93 \pm 1.05 \mathrm{fl}, \mathrm{NS})$.

Conclusions: The above results suggest that MPV cannot be considered a predictor of poor in-hospital outcome in patients with ACS complicated by cardiogenic shock. (Cardiol J 2013; 20, 3: 254-260)

Key words: mean platelet volume, cardiogenic shock, myocardial infarction

\section{Introduction}

Despite great progress in the treatment of acute coronary syndromes (ACS), patients with cardiogenic shock (CS) still remain a group at the greatest risk of death. Simple, easily measurable prognostic factors are sought to distinguish those patients who are at risk of death despite successful recanalization of infarct related artery in CS group.
Platelets are non-nucleated blood cells which play a crucial role in the process of coagulation. Their function is strongly associated with atherogenesis and atherothrombosis - processes important in pathogenesis of cardiovascular diseases [1] Mean platelet volume (MPV) is a widely available parameter of platelet size and function - it is simply measured in most of commonly used blood analyzers, but not yet used in clinical practice.

Address for correspondence: Karolina Supel, MD, Intensive Cardiac Therapy Clinic, Medical University of Lodz, ul. Sterlinga 1/3, 91-425 Łódź, Poland, tel/fax: +48 42664 43 64, e-mail: karolinaewa.k@gmail.com 
Table 1. Baseline characteristic of patients with and without cardiogenic shock.

\begin{tabular}{lccc}
\hline & CS (+), $\mathbf{n}=53$ & CS (-), $\mathbf{n}=53$ & $\mathbf{P}$ \\
\hline Female & $26(49 \%)$ & $26(49 \%)$ & 1.00 \\
Male & $27(51 \%)$ & $28(51 \%)$ & 0.85 \\
Age [years] & $68.9 \pm 11.4$ & $69.1 \pm 10.6$ & 0.65 \\
STEMI & $49(92 \%)$ & $49(92 \%)$ & 1.00 \\
NSTEMI & $4(8 \%)$ & $4(8 \%)$ & 1.00 \\
Prior MI & $12(23 \%)$ & $9(17 \%)$ & 0.46 \\
Smokers & $28(53 \%)$ & $29(55 \%)$ & 0.84 \\
Multivessel disease & $26(57 \%)$ & $24(45 \%)$ & 0.69 \\
Diabetes & $12(23 \%)$ & $14(26 \%)$ & 0.65 \\
Hypertension & $29(55 \%)$ & $36(68 \%)$ & 0.16 \\
Fatal outcome & $29(55 \%)$ & $0(0 \%)$ & $<0.001$ \\
Laboratory results: & & $8.8 \pm 2.85$ & $<0.001$ \\
Blood glucose level $\left[\mathrm{mmol}^{2}\right]$ & $14.76 \pm 6.68$ & $4.51 \pm 0.58$ & 0.97 \\
Red blood cells $\left[10^{6} / \mathrm{mm}^{3}\right]$ & $4.49 \pm 0.57$ & $11.27 \pm 3.33$ & 0.86 \\
White blood cells $\left[10^{3} / \mathrm{mm}^{3}\right]$ & $11.16 \pm 3.09$ & $248.74 \pm 68.08$ & 0.58 \\
Platelets $\left[10^{3} / \mathrm{mm}^{3}\right]$ & $241.25 \pm 68.47$ & $8.57 \pm 0.74$ & 0.25 \\
MPV [fl] & $8.78 \pm 0.89$ & & \\
\hline
\end{tabular}

CS (+) - patients with cardiogenic shock, study group; CS (-) - patients without cardiogenic shock, control group; STEMI - ST-segment elevation myocardial infarction; NSTEMI - non-ST-segment elevation myocardial infarction; MI — myocardial infarction; $\mathrm{MPV}_{1}$ - mean platelet volume on admission; $\mathrm{fl}$ - femtoliter

MPV is a parameter which states platelet size and indirectly proves its activity. It is known that larger platelets are more reactive due to higher concentration of active substances in microgranules (e.g. thromboxane A2 and B2, platelet factor 4, P-selectin, platelet-derived growth factor) and expression of adhesive receptors (glycoprotein IIb/IIIa) [2]. Furthermore, increased MPV values are associated with shortened bleeding time [3].

MPV is considered a useful prognostic marker of cardiovascular risk $[2,4,5]$. In general population, higher MPV value is associated with increased occurrence of myocardial infarction (MI) [2]. Klovaite et al. [6] found that in general Danish population the risk of MI has increased by $38 \%$ in individuals with MPV $\geq 7.4 \mathrm{vs}$. $<7.4 \mathrm{fl}$ independently of known cardiovascular risk factors. Increased MPV value was observed also in patients with hypertension, impaired fasting glucose, diabetes mellitus, hypercholesterolemia and obesity [4, 7].

Increased MPV has been discussed recently as a predictor of death in patients with ACS, but the cut-off point of MPV in relation to poor prognosis has not been estimated so far [2, 4]. MPV value and its clinical significance has not been analyzed in patients with ACS complicated by CS yet. Therefore, we focused on this issue in the present study.

\section{Methods}

\section{Study population}

All consecutive patients with ACS complicated by cardiogenic shock ( $\mathrm{CS}[+]$ group), admitted to the Intensive Cardiac Therapy Clinic during the period from January 2010 to April 2012 and treated with successful primary percutaneous coronary intervention (PCI) were included in our prospective study. Age- and gender-matched patients with uncomplicated ACS were selected as a control group (CS [-] group) (Table 1).

\section{Study protocol}

The diagnosis of ST elevation myocardial infarction (STEMI) was confirmed using the contemporary definition of acute $\mathrm{MI}$ including typical clinical symptoms, persistent ST segment elevation $\geq 0.2 \mathrm{mV}$ in two of $\mathrm{V}_{2}-\mathrm{V}_{3}$ leads or $\geq 0.1 \mathrm{mV}$ in two of other contiguous leads or new left bundle branch block in ECG and elevation of myocardial necrosis markers (troponin $\mathrm{T}$, creatinine kinase-MB fraction) [8]. The diagnosis of non STEMI (NSTEMI) was made on the basis of typical chest pain and elevated cardiac biomarkers after exclusion of elevation of ST-segment in electrocardiography [9]. CS was defined as a clinical state of 
hypoperfusion characterized by a systolic pressure $<90 \mathrm{~mm} \mathrm{Hg}$ (or administration of inotropes and/or intra-aortic balloon pump to maintain systolic blood pressure $>90 \mathrm{~mm} \mathrm{Hg}$ ), oliguria and altered mental status. Other causes of hypotension such as hypovolemia, vasovagal reactions, electrolyte disturbances, pharmacological side-effects, tamponade or arrhythmias were excluded [8]. $\mathrm{Pa}$ tients with $\mathrm{CS}$ as a result of mechanical complications of MI (ventricular septal rupture, acute mitral valve regurgitation) were not included in the study.

Baseline characteristics were obtained for all patients. Demographic data, cardiovascular history, risk factors (hypercholesterolemia, smoking status, hypertension, and diabetes mellitus), and prior embolic events were recorded. We also analyzed the clinical course of hospitalization. Left ventricular function was assessed by echocardiographic examination. Left ventricular end-diastolic and end-systolic volumes and ejection fraction were determined from apical 2- and 4-chamber views using Simpson's biplane formula.

The angiographic severity of coronary artery disease (CAD) was assessed visually using 2 orthogonal views by 2 observers blind to the clinical and echocardiographic details. Single-vessel CAD was defined as at least $70 \%$ stenosis of only one major epicardial artery. Multi-vessel disease was defined as the occurrence of more than one critical stenosis of at least $70 \%$ in a major coronary artery and/or of at least $50 \%$ in the left main coronary artery. The infarct-related artery was identified on the basis of electrocardiography and coronary angiography findings. In general, only the infarct-related artery was treated during emergency catheterization. PCI was performed using standard equipment and techniques including stent implantation. The angiographic success of revascularization was defined as the Thrombolysis In Myocardial Infarction (TIMI) 3 flow.

All patients underwent basic laboratory tests including blood count, electrolytes, coagulation, renal and hepatic parameters, markers of myocardial necrosis and blood glucose levels. MPV was determined on admission and in consecutive 2 days of hospitalization. The blood sample was analyzed immediately after collection in EDTA tubes using an automatic blood counter ABX Pentra XL 80.

The study was approved by the local research ethic committee and all patients were asked for written informed consent.

\section{Statistical analysis}

Statistical analysis of the data was carried out using Statistica 7.0 set. Continuous variables were

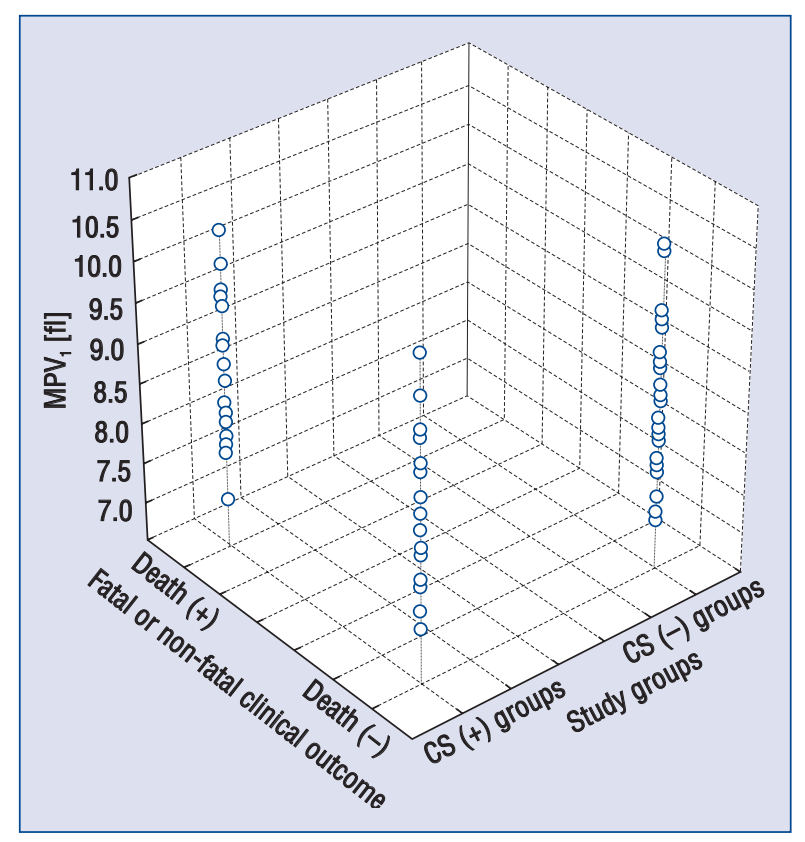

Figure 1. Mean platelet volume on admission in study population; $\mathrm{MPV}_{1}$ - mean platelet volume on admission; CS (+) group - patients with cardiogenic shock, study group; CS (-) group - patients without cardiogenic shock, control group; fl — femtoliter.

presented as means \pm SD. Comparisons between groups were performed using the $\chi^{2}$ test, non-parametric Mann-Whitney test, Friedman test and Wilcoxon test for pairs (post-hoc analysis). Statistical significance was assumed at a $\mathrm{p}$ value of $<0.05$.

\section{Results}

Fifty three patients were included in our study; 53 age- and gender-matched consecutive patients with uncomplicated ACS were selected as a control group. The mean age of patients was $68.9 \pm 11.4$ vs. $69.1 \pm 10.6$ years respectively with $26(49 \%)$ women and $27(51 \%)$ men in both groups. There were $92 \%$ STEMIs and $8 \%$ NSTEMIs both in study and control group. A mortality rate in patients with cardiogenic shock was 29 (55\%) patients which is consistent with previous studies. The majority of deaths (16 patients) occurred on the first day of hospitalization. All patients from the control group survived. Risk factors were evenly distributed in both groups.

$\mathrm{MPV}_{1}$ was similar in both groups $(8.91 \pm 1.11 \mathrm{fl}$ vs. $8.57 \pm 0.74 \mathrm{fl}, \mathrm{NS}$ ) (Fig. 1). In subsequent days of hospitalization mean MPV was increasing in patients with and without CS, but more in the latter. In study group, the increase in MPV value 
Table 2. Comparison of mean platelet volume in patients with and without cardiogenic shock in consecutive days.

\begin{tabular}{|c|c|c|c|c|c|c|}
\hline & \multicolumn{2}{|c|}{$\operatorname{CS}(+)$} & \multicolumn{2}{|c|}{ CS (-) } & \multirow[t]{2}{*}{$z$ value } & \multirow[t]{2}{*}{ p value } \\
\hline & $\mathbf{x}$ & SD & $x$ & SD & & \\
\hline $\mathrm{MPV}_{1}[\mathrm{fl}]$ & 8.91 & 1.11 & 8.57 & 0.74 & 1.365 & $>0.05$ \\
\hline $\mathrm{MPV}_{2}[\mathrm{fl}]$ & 9.19 & 0.80 & 8.84 & 0.86 & 1.989 & $<0.05$ \\
\hline $\mathrm{MPV}_{3}[\mathrm{fl}]$ & 9.39 & 0.95 & 9.11 & 0.89 & 1.132 & $>0.05$ \\
\hline
\end{tabular}

CS $(+)$ - patients with cardiogenic shock, study group; CS (-) - patients without cardiogenic shock, control group; MPV - mean platelet volume on admission; $\mathrm{MPV}_{2}$ — mean platelet volume on the second day; $\mathrm{MPV}_{3}$ - mean platelet volume on the third day; SD - standard deviation; $\mathrm{fl}$ — femtoliter

Table 3. Comparison of mean platelet volume in patients with fatal and non-fatal cardiogenic shock in consecutive days.

\begin{tabular}{|c|c|c|c|c|c|c|}
\hline & \multicolumn{2}{|c|}{ Fatal CS } & \multicolumn{2}{|c|}{ Non-fatal CS } & \multirow[t]{2}{*}{ z value } & \multirow[t]{2}{*}{ p value } \\
\hline & $\mathbf{x}$ & SD & $\mathbf{x}$ & SD & & \\
\hline $\mathrm{MPV}_{1}[\mathrm{fI}]$ & 8.90 & 1.18 & 8.93 & 1.05 & 0.232 & $>0.05$ \\
\hline $\mathrm{MPV}_{2}[\mathrm{fl}]$ & 9.25 & 0.80 & 9.16 & 0.81 & 0.382 & $>0.05$ \\
\hline $\mathrm{MPV}_{3}[\mathrm{fl}]$ & 9.35 & 0.83 & 9.40 & 1.00 & 0.135 & $>0.05$ \\
\hline
\end{tabular}

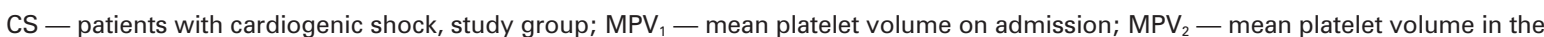
second day; $\mathrm{MPV}_{3}$ — mean platelet volume in the third day; SD — standard deviation; fl — femtoliter

was significant when comparing MPV value on admission and on the third day $(8.91 \pm 1.11 \mathrm{fl}$ vs. $9.39 \pm 0.95 \mathrm{fl}, \mathrm{MPV}_{1}$ vs. $\left.\mathrm{MPV}_{3} \mathrm{z}=2.848, \mathrm{p}<0.01\right)$. In contrast, in control group MPV was significantly increasing in consecutive days $\left(\mathrm{MPV}_{1}: 8.57 \pm 0.74 \mathrm{fl}\right.$, $\mathrm{MPV}_{1}$ vs. $\mathrm{MPV}_{2} \mathrm{z}=4.178, \mathrm{p}<0.001 ; \mathrm{MPV}_{2}: 8.84 \pm$ $\pm 0.86 \mathrm{fl}, \mathrm{MPV}_{1}$ vs. $\mathrm{MPV}_{3} \mathrm{z}=4.678, \mathrm{p}<0.001$ $\mathrm{MPV}_{3}: 9.11 \pm 0.89 \mathrm{fl}, \mathrm{MPV}_{2}$ vs. $\mathrm{MPV}_{3} \mathrm{Z}=2.818$ $\mathrm{p}<0.01)$. Mean MPV was significantly higher in patients with CS in comparison to control group only on the second day after onset of symptoms $\left(\mathrm{MPV}_{2}\right.$ : $9.19 \pm 0.8 \mathrm{fl}$ vs. $8.84 \pm 0.86, \mathrm{p}<0.05$ ) (Table 2). Furthermore, there were no statistically significant differences in $\mathrm{MPV}_{1}$ value in fatal and nonfatal CS $(8.90 \pm 1.18 \mathrm{fl}$ vs. $8.93 \pm 1.05 \mathrm{fl}, \mathrm{NS})$ (Table 3$). \mathrm{In}$ the multiple stepwise logistic regression analysis of biochemical $\left(\mathrm{MPV}_{1}\right.$, blood glucose and creatinine level) and clinical factors (age, sex, history of diabetes) none of the factors was found to be a predictor of death in CS (+) group. In addition, no correlation was found between MPV $\mathrm{V}_{1}$ and blood glucose level on admission in $\mathrm{CS}(+)(\mathrm{r}=-0.1702, \mathrm{p}=0.22)$ and in $\mathrm{CS}(-)$ group $(\mathrm{r}=0.1207, \mathrm{p}=0.4)$ likewise (Fig. 2).

\section{Discussion}

Platelets are formed in the bone marrow from the polyploid megakaryocytes. Their volume is regulated by molecular mechanisms and growth factors and doesn't correlate with the age of platelets [2]. It is influenced by thrombopoietin (TPO), interleukin-6 and -3 [2]. TPO is a main regulator of megakaryocytopoiesis. It also stimulates alpha granule secretion from platelets and enhances their ability to aggregate [10]. TPO was positively correlated with MPV in ACS patients in the report of Senaran et al. [11].

It is known that, among other blood parameters, platelets count and mean platelet volume are mostly inheritable. Meisinger et al. [12] identified three loci and three common single-nucleotide polimorphisms associated with MPV, which stand for about 5\% of MPV value variances in population. In Soranzo et al. [13] genome wide association study one quantitative trait loci associated with MPV, located at 12q24, was also a risk locus for $\mathrm{CAD}$. It requires further studies and their results may contribute to the understanding of the relationship between MPV, platelets function and cardiovascular risk $[12,14]$.

There is no relevant difference between MI and unstable angina group in contrast with stable angina, in which mean MPV is on a similar level as in healthy controls [2, 15]. Likewise, MPV is higher in MI with normal coronary arteries compared to control subjects [16]. The important clinical implication of MPV is its predictive value of coronary angioplasty effectiveness. The Chu 


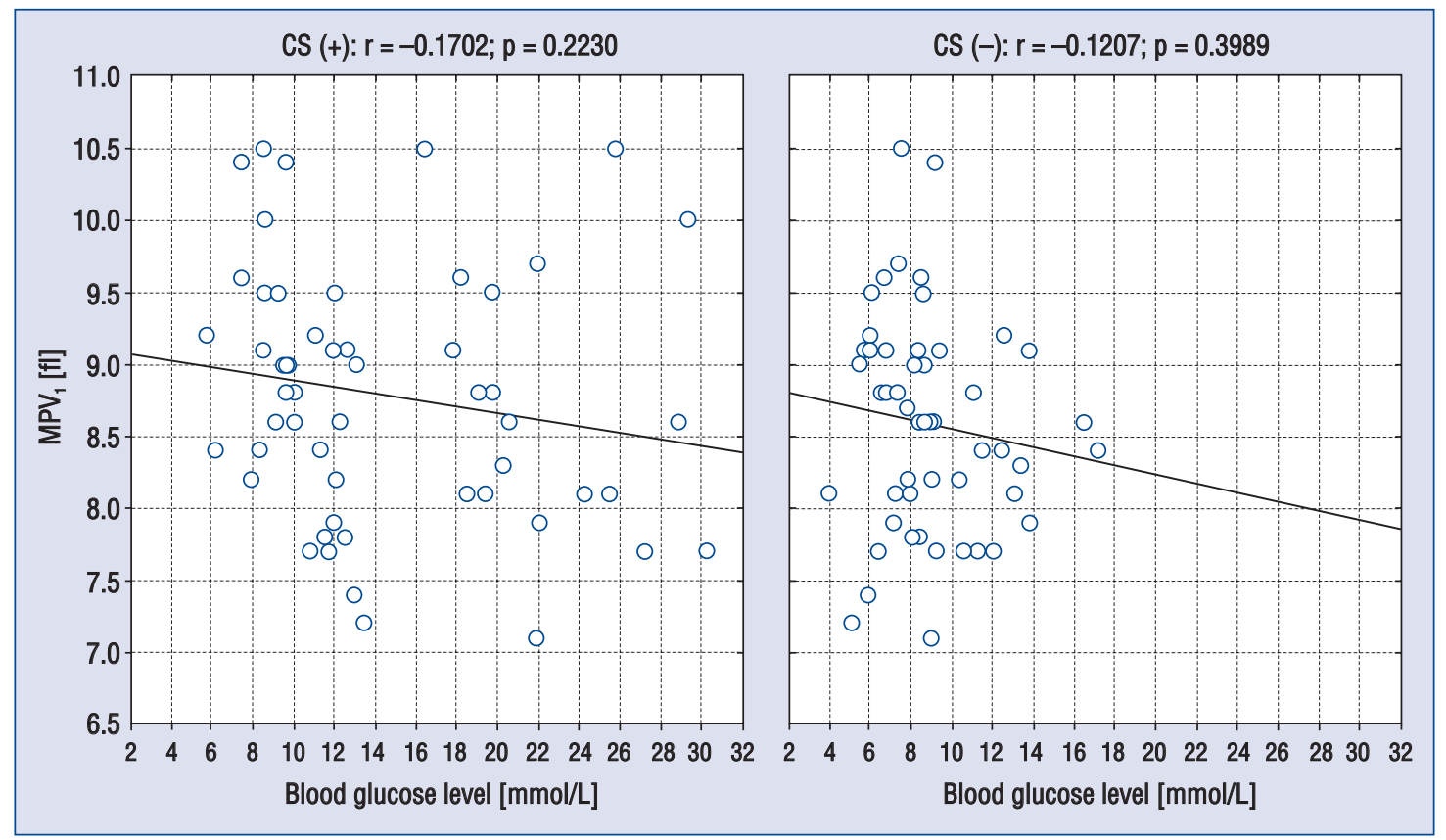

Figure 2. Correlation between mean platelet volume and blood glucose level on admission in patients with and without cardiogenic shock, respectively; $\mathrm{MPV}_{1}$ - mean platelet volume on admission; $\mathrm{CS}(+)$ - patients with cardiogenic shock, study group; CS (-) — patients without cardiogenic shock, control group; fl — femtoliter.

et al. [2] study has shown significantly higher baseline mean MPV in patients who developed restenosis than in those who did not develop such a complication. A similar correlation was found by Huczek et al. [17]. Also the study by Taglieri et al. [7] revealed a trend toward higher incidence of stent thrombosis. Duygu et al. [18] considered MPV a useful hematological marker allowing identification of patients with stable CAD who are at higher risk of post-PCI low-reflow.

Elevated MPV has been discussed recently as a predictor of death in patients with ACS, but the cut-off point of MPV in relation to poor prognosis has not been estimated so far.

In some studies conducted in AMI, elevated MPV was associated with higher risk of death and recurrent infarction not only in hospital but also during the 2 years observation after ACS [2, 19-22]. Taglieri et al. [7] investigated higher risk of primary end-point, composed of cardiovascular death and re-MI at 1 year after ACS in patients with NSTEMI with MPV $\geq 8.9 \mathrm{fl}$. Chu et al. [2] reported the 2 -fold increase in mortality among acute MI patients with MPV cut off point of $\geq 10.3 \mathrm{fl}$ in comparison to a group with the cut-off point of $9 \mathrm{fl}$ [2]. In the study by Dogan et al. [23] major cardiac outcome (consisting of the composite end-point of cardiac death, MI, recurrent angina and hospitalization) in NSTEMI patients at 12 months was significantly higher in group with MPV $>9.9 \mathrm{fl}$ (39\% vs. $26 \%, p=0.016)$. Some values of higher risk are postulated in research, but the increase of cardiovascular risk may remain in linear relationship with increasing MPV.

On the contrary, Lopez-Cuenca et al. [24] revealed that MPV did not show an independent prognostic significance at 6-month follow-up in their NSTEMI group. Azab et al. [25] found that MPV/ /platelet count ratio is superior to the MPV alone in predicting long-term mortality after NSTEMI. They suggested that usage of this ratio would magnify the relationship between platelet indices and mortality after NSTEMI.

In our study we evaluated the prognostic value of MPV in ACS complicated by cardiogenic shock. Such an analysis in patients with the most serious and fatal complication of ACS has not been performed so far. Mean MPV was significantly higher in patients with CS in comparison to the control group only in the second day after onset of symptoms $\left(\mathrm{MPV}_{2}\right)$. There were no statistically significant differences in MPV value in fatal and nonfatal CS. We proved that MPV could not be considered as a predictor of 
poor in-hospital outcome in patients with ACS complicated by cardiogenic shock.

Diabetic patients are in danger of micro- and macrovascular complications. Hyperglycemia leads to endothelial damage through oxidative and osmotic stress, advanced glycation end products, decreased nitrogen monoxide production and epigenetic changes in gene promoters resulting in persistent inflammation [26]. Platelet dysfunction and increased thromboxane A2 synthesis lead to prothrombotic state in diabetes mellitus [27]. Zuberi et al. [28] have reported that MPV is increased in hyperglycemia states - its value rises significantly from non-diabetic patients through impaired fasting glucose patients to diabetic population group (mean MPV $8.63 \mathrm{fl}, 8.98 \mathrm{fl}, 9.34 \mathrm{fl}$, respectively). It means that changes in megacaryocyte - platelet axis which occur before ACS may be similar to those present in pre-diabetic conditions. Klodiatte et al. [29] suggested that MPV would be a useful prognostic marker of cardiovascular complications in diabetes. They found that increase in $\mathrm{HbA} 1 \mathrm{c}$ concentration was directly proportional to increased MPV in their diabetic group composed of 255 individuals. The mean MPV in the subgroup with $\mathrm{HbA} 1 \mathrm{c}<6.5 \%$ was significantly lower in comparison to the subgroup with $\mathrm{HbA1c}>6.5 \%(7.95 \pm$ $\pm 0.72 \mathrm{fl} \mathrm{vs.} 8.35 \pm 0.72 \mathrm{fl})$. However, in our study, we found no correlation between $\mathrm{MPV}_{1}$ and blood glucose level on admission neither in patients with cardiogenic shock nor in the control group. There is no evidence that osmotic stress can cause platelets enlargement through higher permeability of the cellular membrane.

\section{Limitations of the study}

The small group of patients is the most important limitation of this study. Cardiogenic shock develops in 6-9\% of patients with ACS. The high mortality rate in CS results in loss of data for analysis in consecutive days. There were no studies devoted to assessment of the predictive value of MPV in patients with cardiogenic shock, therefore further studies on this topic are required to confirm our results.

\section{Conclusions}

The above results from our relatively small group suggest that MPV could not be considered a predictor of poor in-hospital outcome in patients with ACS complicated by cardiogenic shock.

\section{Conflict of interest: none declared}

\section{References}

1. Davi G, Patrono C. Platelet activation and atherothrombosis. N Engl J Med, 2007; 357: 2482-2494.

2. Chu SG, Berger RC, Bhatt DL et al. Mean platelet volume as a predictor of cardiovascular risk: A systematic review and meta-analysis. J Thromb Haemost, 2010; 8: 148-156.

3. Maden O, Kacmaz F, Selcuk H et al. Relstionship of admission hematological indexes with myocardial reperfusion abnormalities in acute ST segment elevation myocardial infarction patients treated with primary percutaneous coronary interventions. Can J Cardiol, 2009; 25: e164-e168.

4. Vizioli L, Muscari S, Muscari A. The relationship of mean platelet volume with the risk and prognosis of cardiovascular diseases. Int J Clin Pract, 2009; 63: 1509-1515.

5. Slavka G, Perkmann T, Haslacher H et al. Mean platelet volume may represent a predictive parameter for overall vascular mortality and ischeamic heart disease. Arterioscler Thromb Vasc Biol, 2011; 31: 1215-1218.

6. Klovaite J, Benn M, Yazdanyar S, Nordestgaard BG. High plaelet volume and increased risk of myocardial infarction: 39531 participants from the general population. J Thromb Haemost, 2011; 9: 49-56.

7. Taglieri N, Saia F, Rapezi Cet al. Prognostic significance of mean platelet volume on admission in an unselected cohort of patients with non ST-segment elevation acute coronary syndrome. Thrombosis Haemost, 2011; 106: 132-140.

8. ESC Guidelines: Mangement of acute myocardial infarction in patients presenting with persistent ST-segment elevation. EHJ, 2008; 29: 2909-2945.

9. ECS Guidelines for the management of acute coronary syndromes in patients presenting without persistent ST-segment elevation. EHJ, 2011; 32: 2999-3054.

10. Deutsch V, Tomer A. Megakaryocyte development and platelet production. Br J Hematol, 2006; 134: 453-466.

11. Senaran H, Ileri M, Altinbas A et al. Thrombopoietin and mean platelet volume in coronary artery disease. Clin Cardiol, 2001; 24: 405-408.

12. Meinsinger $\mathrm{Ch}$, Prokisch $\mathrm{H}$, Gleger $\mathrm{Ch}$ et al. A genome-wide association study identifies three loci associted with mean platelet volume. Am J Human Genetics, 2009; 84: 66-71.

13. Soranzo N, Spector TD, Mangino M et al. A genome-wide meta-analysis identifies 22 loci associated with eight hematological parameters in the HaemGen consortium. Nat Genet, 2009; 41: 1182-1190.

14. Kunicki TJ, Nugent DJ. The genetics of normal platelet reactivity. Blood, 2010; 116: 2627-2634.

15. Khandekar MM, Khurana AS, Deshmukh SD, Kakrani AL, Katdare AD, Inamdar AK. Platelet volume indices in patients with coronary artery disease and acute myocardial infarction: An Indian scenario. J Clin Pathol, 2006; 59: 146-149.

16. Varol E, Icli A, Ozaydin M, Erdogan D, Arslan A. Mean platelet volume is elevated in patients with myocardial infarction with normal coronary arteries, as in patients with myocardial infarction with obstructive coronary artery disease. Scand J Clin Lab Invest, 2009; 69: 570-574.

17. Huczek Z, Filipiak KJ, Kochman J et al. Baseline platelet size is increased in patients with acute coronary syndromes developing early stent thrombosis and predicts future residual platelet reactivity. A case-control study. Throm Res, 2010; 125: 406-412. 
18. Duygu H, Turkoglu C, Kirilmaz B, Turk U. Effect of mean platelet volume on postintervension coronary blood flow in patients with chronic stable angina pectoris. J Invasive Cardiol, 2008; 20: 120-124.

19. Tekbas E, Kara AF, Ariturk $Z$ et al. Mean platelet volume in predicting short-and long therm morbidity and mortality in patients with or without ST-segment elevation myocardial infarction. Scand J Clin Lab Invest, 2011; 71: 613-619.

20. Slavka G, Perkmann T, Haslacher H et al. Mean platelet volume may represent a predictive parameter for overall vascular mortality and ischemic heart disease. Arterioscler Thromb Vasc Biol, 2011; 31: 1215-1218.

21. Yasar AS, Bilen E, Yuksel I et al. Association between admission mean platelet volume and coronary patency after thrombolytic therapy for acute myocardial infarction. Arch Turk Soc Cardiol, 2010; 38: 85-89.

22. Martin JF, Bath PM, Burr ML. Influence of platelet size on outcome after myocardial infarction. Lancet, 1991; 338: 1409-1411.

23. Dogan A, Aksoy F, Icli A et al. Mean platelet volume is associated with culprit lesion severity and cardiac events in acute coronary syndromes without ST elevation. Blood Coagul Fibrinolysis, 2012; 23: 324-330.

24. Lopez-Cuenca AA, Tello-Montoliu A, Roldan V, Perez-Berbel P, Valdes M, Marin F. Prognostic value of mean platelet volume in patients with non-ST-elevation acute coronary syndrome. Angiology, 2012; 63: 241-244.

25. Azab B, Torbey E, Singh J et al. Mean platelet volume/platelet count ratio as a predictor of long term mortality after nonST elevation myocardial infarction. Platelets, 2011; 22: 557-566.

26. Reusch J, Low Wang C. Cardiovascular disease in diabetes: Where does glucose fit in? J Clin Endocrinol Metab, 2011; 96: 2367-2376.

27. Cerbone AM, Macarone-Palmieri N, Saldalamacchia G, Coppola A, Di Minno G, Rivellese AA. Diabetes, vascular complications and antiplatelet therapy: Open problems. Acta Diabetol, 2009; 46: 253-261.

28. Zuberi BF, AKhtar N, Asfar S. Comparison of mean platelet volume in patients with diabetes mellitus, impaired fasting glucose and non-diabetic subjects. Singapore Med J, 2008; 49: 114.

29. Klodiatte T, Manikyam U, Rao S et al. Mean platelet volume in type 2 diabetes mellitus. J Lab Physicians, 2012; 4: 5-9. 